
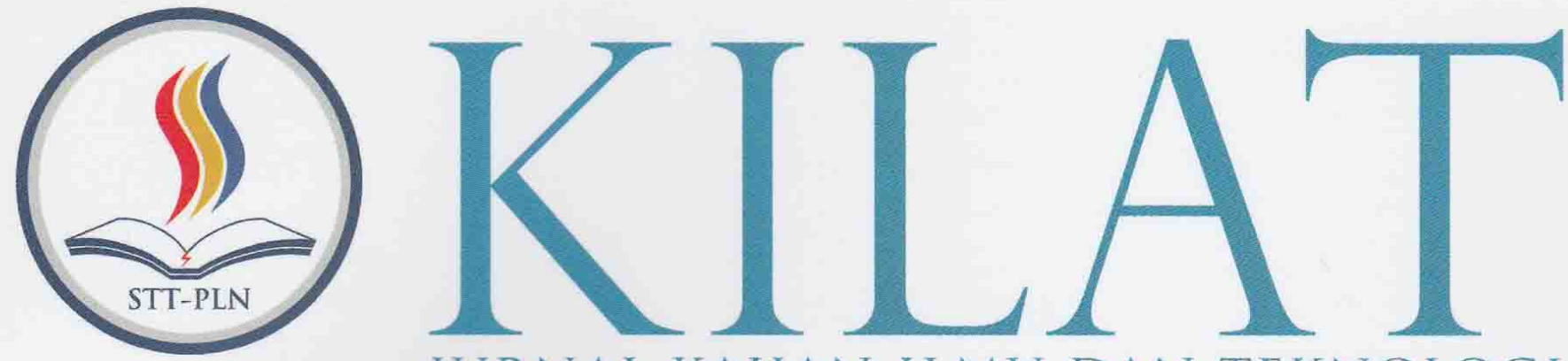

JURNAL KAJIAN ILMU DAN TEKNOLOGI

Endah Lestari: Irma Wirantina K: Ranti Hidayawanti

Faisal:

Muhammad Ridwan: Mardawati

Gita Puspa Artiani: Indah Handayasari

Kresna Ramanda; Irmawati Carolina

Ratna Mutu Manikam:

Farid Setiawan

Rayung Wulan

Roni Kartika Pramuyanti

Rr. Mekar Ageng Kinasti; Djoko Nugroho Notodisuryo

Satria;

Ayu Setiawati Agustini

Syam Gunawan: Pritasari Palupiningsih

Ali Ridho Gumelar: Anton: Ummu Radiyah

M. Yoga Distra Sudirman: Yessy Fitriani
ANALISA TAMAN ATAP DALAM UPAYA MENGURANGI LIMPASAN AIR HUJAN PADA BANGUNAN PERKOTAAN

OPTIMASI DIAGRAM LAYANAN PEMBELIAN DALAM MENDUKUNG MANAJEMEN HUBUNGAN PELANGGAN

OPTIMALISASI PENGOLAHAN SAMPAH ORGANIK DENGAN TEKNOLOGI BIODIGESTER SEBAGAI UPAYA KONSERVASI LINGKUNGAN

SELEKSI FITUR ALGORITMA NEURAL NETWORK MENGGUNAKAN PARTICLE SWARM OPTIMIZATION UNTUK MEMPREDIKSI KELAHIRAN PREMATUR

RANCANG BANGUN MEDIA BELAJAR FISIKA DASAR UNTUK MAHASISWA BERBASIS ANDROID

ANALISIS GLOBAL POSITIONING INFRASTRUKTUR DAN JARINGAN SOSIAL MEDIA DALAM BISNIS APLIKASI TRANSPORTASI DARAT ONLINE DI JAKARTA

PENGARUH INOVASI ANTENA PADA SIARAN TELEVISI MOBIL

PEMANFAATAN LIMBAH PEMBAKARAN BATUBARA (BOTTOM ASH) PADA PLTU SURALAYA SEBAGAI MEDIA TANAM DALAM UPAYA MENGURANGI PENCEMARAN LINGKUNGAN

PENERAPAN METODE GRAPHIC RATING SCALE (GRS) DALAM PENILAIAN KINERJA KARYAWAN

PEMBENTUKAN MODEL KLASIFIKASI DATA LAMA STUDI MAHASISWA STMIK INDONESIA MENGGUNAKAN DECISION TREE DENGAN ALGORITMA NBTREE

IMPLEMENTASI LOAD BALANCING DENGAN ALGORITMA EQUAL COST MULTI PATH (ECMP)

RANCANGAN SISTEM PENILAIAN HASIL KINERJA MULTI COMPANY DAN CROSS BUSINESS SECTOR 


\title{
PENERAPAN METODE GRAPHIC RATING SCALE (GRS) DALAM PENILAIAN KINERJA KARYAWAN
}

\author{
${ }^{1}$ Satria; ${ }^{2}$ Ayu Setiawati Agustini \\ ${ }^{1}$ Program Studi/Jurusan Sistem Informasi, STMIK Bani Saleh,email: satria1905@gmail.com \\ ${ }^{2}$ Program Studi/Jurusan Sistem Informasi, STMIK Bani Saleh, email: tia.agustini30@gmail.com
}

\begin{abstract}
ABSTRAK
Persaingan bisnis yang semakin kompetitif memicu Perusahaan Muliadana untuk lebih inovatif dalam meningkatkan kualitas perusahaan. Salah satu teknik yang digunakan manajemen perusahaan dalam meningkatkan kualitas sumber daya manusia adalah dengan melakukan penilaian kinerja karyawan. Untuk itu penulis mencoba membuat sistem penilaian dengan menggunakan metode Graphic Rating Scale (GRS), yaitu suatu metode penilaian dengan skala grafik dengan membandingkan kinerja individu terhadap sebuah standar yang absolute. Tujuan dari metode penilaian ini adalah untuk meminimalisir penilaian yang kurang objektif dan dapat mengetahui perkembangan kinerja karyawan selama beberapa periode. Hasil dari penilaian kinerja karyawan adalah perusahaan dapat memberikan umpan balik kepada para karyawan sehingga bisa memutuskan langkah yang diambil dalam pengambilan keputusan seperti : promosi, kenaikan jabatan maupun golongan, mutasi, degradasi maupun pelatihan terhadap karyawan yang membutuhkan.
\end{abstract}

Kata Kunci : Penilaian Kinerja, Karyawan, Graphic Rating Scale (GRS)

\section{ABSTRACT}

Competition increasingly competitive business trigger Muliadana company to be more innovative in improving the quality of the company. One technique used by management companies in improving the quality of human resources is to conduct employee performance appraisal. To the authors try to establish a scoring system using the Graphic Rating Scale (GRS), which is a methodology for assessing the scale of the graph by comparing the individual performance against an absolute standard. The purpose of this valuation method is to minimize the less objective assessment and can determine the development of the employee's performance over several periods. The results of the performance appraisal company can provide feedback to the employees so they can decide the steps taken in making decisions such as: promotion, promotion or class, mutation, degradation as well as training for employees in need.

Keywords: Performance Assessment, Employees, Graphic Rating Scale (GRS)

\section{PENDAHULUAN}

\subsection{Latar Belakang}

Penilaian kinerja karyawan ini juga berguna bagi perusahaan dalam memberi umpan balik kepada karyawan dan dapat dijadikan dasar perusahaan untuk melakukan promosi, kenaikan jabatan atau golongan, mutasi, degradasi maupun pelatihan terhadap karyawan yang membutuhkan.

Permasalahn yang dihadapi dalam penilaian kinerja di Koperasi Simpan Pinjam Muliadana adalah penilaian kinerja yang selama ini dilakukan masih menggunakan penilaian yang masih tradisional dimana seorang atasan menilai langsung bawahannya tanpa adanya standar penilaian yang absolut. Penilaian kurang obyektif, dikarenakan ada beberapa kriteria yang tidak ada data pendukungnya seperti kriteria penilaian untuk kemampuan pribadi, sehingga penilaian dilakukan berdasarkan pendapat pribadi seorang penilai/ atasan. Selain itu sistem penilaian yang ada sekarang belum bisa mengolah data-data penilaian kinerja yang berguna untuk memvalidasi penilaian dan menjaga keakuratan data-data yang dipakai. Dari beberapa kondisi tersebut membuat penyampaian informasi perbandingan kinerja pegawai selama satu periode dan pegawai mana yang memperoleh nilai kinerja baik dan nilai kinerja buruk membutuhkan waktu yang lama pula.

Berdasarkan permasalahan di atas maka dibutuhkan sebuah sistem informasi penilaian kinerja karyawan yang terkomputerisasi yang mampu mempercepat proses perhitungan, mengolah data-data yang berguna untuk validasi penilaian kinerja dan menjaga keakuratan data, serta membuat penilaian yang lebih obyektif dengan menetapkan parameter/kriteria yang sesuai dengan bidangnya sehingga dapat menjadi acuan dalam proses penilaian. Untuk itu penulis mencoba membuat sistem penilaian dengan menggunakan metode Graphic Rating Scale (GRS). GRS atau skala penilaian grafik adalah membandingkan kinerja individu terhadap sebuah standar yang absolut. Penilai mengevaluasi kinerja dari berbagai dimensi atau kriteria.

Dalam penelitian Harni Mukti Wahyuning (2015) menjelaskan bahwa Metode graphic rating scale (GRS) yang dapat mengambil keputusan secara tepat dan akurat.

\subsection{Tujuan Penelitian}

a. Penilaian kinerja karyawan selama ini masih menggunakan cara yang tradisional yaitu dimana seorang Atasan menilai langsung 
bawahannya tanpa adanya standar kriteria yang absolut sehingga penilai menjadi kurang objektif.

b. Sistem penilaian yang ada sekarang belum bisa mengolah data-data penilaian kinerja karyawan yang berguna untuk memvalidasi dan menjaga keakuratan data-data yang dipakai dan belum terdokumentasi dengan baik.

\section{METODOLOGI PENELITIAN}

\subsection{Sistem Informasi}

Sistem informasi adalah sistem didalam suatu organisasi yang mempertemukan kebutuhan pengolahan transaksi harian, mendukung operasi yang bersifat manajerial dan kegiatan strategi dari suatu organisasi dan menyediakan pihak luar tertentu dengan laporan-laporan yang diperlukan. (Tata Sutabri, 2004:36).

\subsection{Kinerja}

"Kinerja (performance) adalah hasil pekerjaan yang dicapai seseorang berdasarkan persyaratanpersyaratan pekerjaan (Job Requirement)". Pekerjaan mempunyai persyaratan tertentu untuk dapat dilakukan dalam mencapai tujuan yang disebut juga sebagai standar pekerjaan (job standart)". (Wilson Bangun, 2012:231).

\subsection{Penilaian Kinerja}

"Penilaian Kinerja adalah proses yang dilakukan organisasi untuk mengevaluasi atau menilai keberhasilan karyawan dalam melaksanakan tugasnya, penilaian dapat dilakukan dengan membandingkan hasil kerja yang dicapai karyawan dengan standar pekerjaan". (Wilson Bangun, 2012:231).

"Penilaian Kinerja adalah proses evaluasi seberapa baik karyawan mengerjakan pekerjaan mereka ketika dibandingkan dengan satu set standar, dan kemudian mengkomunikasikannya dengan para karyawan ". (Jackson Robert L. Mathis \& John H, 2006:81).

\subsection{Metode Graphic Rating Scales (GRS)}

Metode GRS adalah metode penilaian yang membagi lima kategori penilaian untuk setiap faktor penilaian, faktor yang dijadikan penilaian harus terukur agar penilaian dapat dilakukan secara objektif. Lima faktor itu adalah : Sangat buruk, buruk, sedang, baik, dan sangat baik. (Wilson Bangun, 2012:242).

"GRS adalah skala yang digunakan untuk memberikan nilai (Rating) ke suatu variabel". (Jogiyanto Hartono, 2008:130). adalah :

Beberapa skala rating yang sering digunakan
a. Skala dikotomi
Skala ini memberikan nilai dikotomi missal nilai ya atau tidak
b. Skala kategori
Skala ini memberikan nilai beberapa item untuk dipilih, tipe data yang digunakan adalah tipe nominal.
c. Skala likert

Skala ini digunakan untuk mengukur respon subyek ke dalam 5 poin atau 7 pon skala interval yang sama.

d. Skala perbedaan semantik

Skala ini menggunakan dua buah nilai ekstrim dan subyek diminta untuk menentukan responnya diantara dua nilai tersebut diruang yang disediakan yang disebut dengan nilai semantik.

e. Skala numeric

Skala ini sama dengan skala semantik hanya mengganti ruang semantik yang digunakan dengan angka-angka numerik (misalnya nilai 1 sampai 5 untuk poin skala likert atau 1 sampai 7 untuk 7 poin skala likert, tipe data yang digunakan adalah tipe interval.

f. Skala penjumlahan tetap

Subyek diminta untuk mendistribusikan nilai responnya kedalam beberapa item yang sudah disediakan dengan jumlah tetap, tipe data yang digunakan adalah tipe rasio.

g. Skala staple

Skala ini dimaksudkan tidak hanya mengukur niattas respon dari subyek tetapi juga arah responnya. Karena nilai nol tidak disebutkan dengan eksplisit, tipe data yang digunakan adalah tipe interval

h. Skala grafik

Skala ini menggunakan grafik skala dan subyek member tanda pada tempat di grafik untuk responnya, tipe data yang digunakan adalah tipe interval.

Dari kedua definisi diatas dapat disimpulkan bahwa metode GRS adalah suatu metode penilaian yang membandingkan kinerja individu terhadap standar absolut dimana penilaian meliputi beberapa kriteria antara lain : kedisiplinan, kualitas pekerjaan dan lain-lain.

Skala yang digunakan mudah digunakan dan dipahami kepada karyawan yang dinilai. Skala penilaian grafik memberikan penilaian yang khas. Disitu didaftarkan ciri-ciri (seperti mutu dan kehandalan) serta kisaran nilai kinerja (dari yang tidak memuaskan sampai yang luar biasa memuaskan) untuk masing-masing bawahan dengan melingkari atau memeriksa skor yang paling baik menggambarkan kinerjanya untuk masingmasing ciri.

\section{Proses Penilaian}

Proses perhitungan penilaian: Langkahlangkah dalam proses penilaian:

1. Menentukan kriteria apa saja yang akan dinilai dan bobotnya

2. Menentukan subkriteria

3. Menentukan bobot jenis penilai

4. Menentukan periode penilaian

5. Menentukan penilai dan pegawai yang akan dinilai

Berikut contoh penentuan berdasarkan survey yg dilakukan di perusahaan dan bisa berubah sesuai kebijakan koperasi simpan pinjam : 
Tabel 1. Tabel Bobot Kriteria

\begin{tabular}{|c|l|l|l|}
\hline \multirow{2}{*}{ No } & \multirow{2}{*}{ kriteria } & \multicolumn{2}{|c|}{ Persentase tiap level (\%) } \\
\cline { 3 - 4 } & & Kepala Unit & HRD \\
\hline 1 & Achievement & 30 & 30 \\
\hline 2 & Ability & 30 & 30 \\
\hline 3 & Attitude & 40 & 40 \\
\hline
\end{tabular}

Tabel 2. Tabel Kriteria Penilaian

\begin{tabular}{|l|l|l|l|}
\hline No & \multicolumn{1}{|c|}{ kriteria } & \multicolumn{1}{|c|}{$\begin{array}{c}\text { deskripsi_- } \\
\text { kriteria }\end{array}$} & $\begin{array}{c}\text { Presen- } \\
\text { tase (\%) }\end{array}$ \\
\hline 1 & Achievement & $\begin{array}{l}\text { Pencapaian } \\
\text { Target }\end{array}$ & 10 \\
\hline 2 & Achievement & $\begin{array}{l}\text { Kualitas } \\
\text { Pekerjaan }\end{array}$ & 10 \\
\hline 3 & Achievement & $\begin{array}{l}\text { Ketepatan } \\
\text { Tugas }\end{array}$ & 10 \\
\hline 4 & Ability & $\begin{array}{l}\text { Pekerjaan } \\
\text { Sesuai SOP }\end{array}$ & 15 \\
\hline 5 & Ability & $\begin{array}{l}\text { Kemampuan } \\
\text { dalam Team }\end{array}$ & 15 \\
\hline 6 & Ability & $\begin{array}{l}\text { Tanggung jawab } \\
\text { Terhadap } \\
\text { Pekerjaan }\end{array}$ & 10 \\
\hline 7 & Attitude & $\begin{array}{l}\text { Kehadiran } \\
\text { Karyawan }\end{array}$ & 15 \\
\hline 8 & Attitude & $\begin{array}{l}\text { Ketepatan } \\
\text { Waktu }\end{array}$ & 15 \\
\hline
\end{tabular}

Tabel 3 Tabel Bobot Jenis Penilai

\begin{tabular}{|c|l|c|}
\hline No & Jenis Penilai & Presentase (\%) \\
\hline 1 & Kepala Unit & 100 \\
\hline
\end{tabular}

Rumus Perhitungan :

Karena hanya 1 penilai :

Nilai Kriteria $_{\mathrm{i}}=\sum_{\mathrm{j}=1}^{\mathrm{n}}($ Nilai Subkriteria $i j *$ bobot $i j)$

Keterangan :

Nilai Kriteria $\mathrm{i}=$ total nilai dari subkriteria ke-i

Nilai Subkriteria ij = nilai subkriteria dari kriteria ke-i pada bobot ke-j

Bobot ij = tingkat kepentingan (bobot) kriteria ke-j $\mathrm{i}=$ 1,2,3...n;

$\mathrm{n}=$ jumlah kriteria $\mathrm{j}=1,2,3 \ldots \mathrm{m}$;

$\mathrm{m}=$ jumlah bobot

\section{HASIL DAN PEMBAHASAN}

\subsection{Rancangan Sistem}

Form yang berasal dari Koperasi Simpan Pinjam Muliadana.

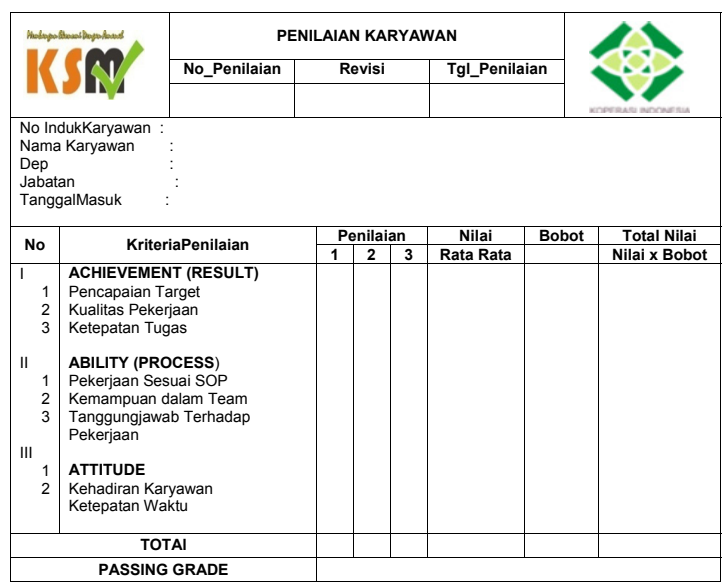

\subsection{Flowmap sistem yang sedang berjalan}

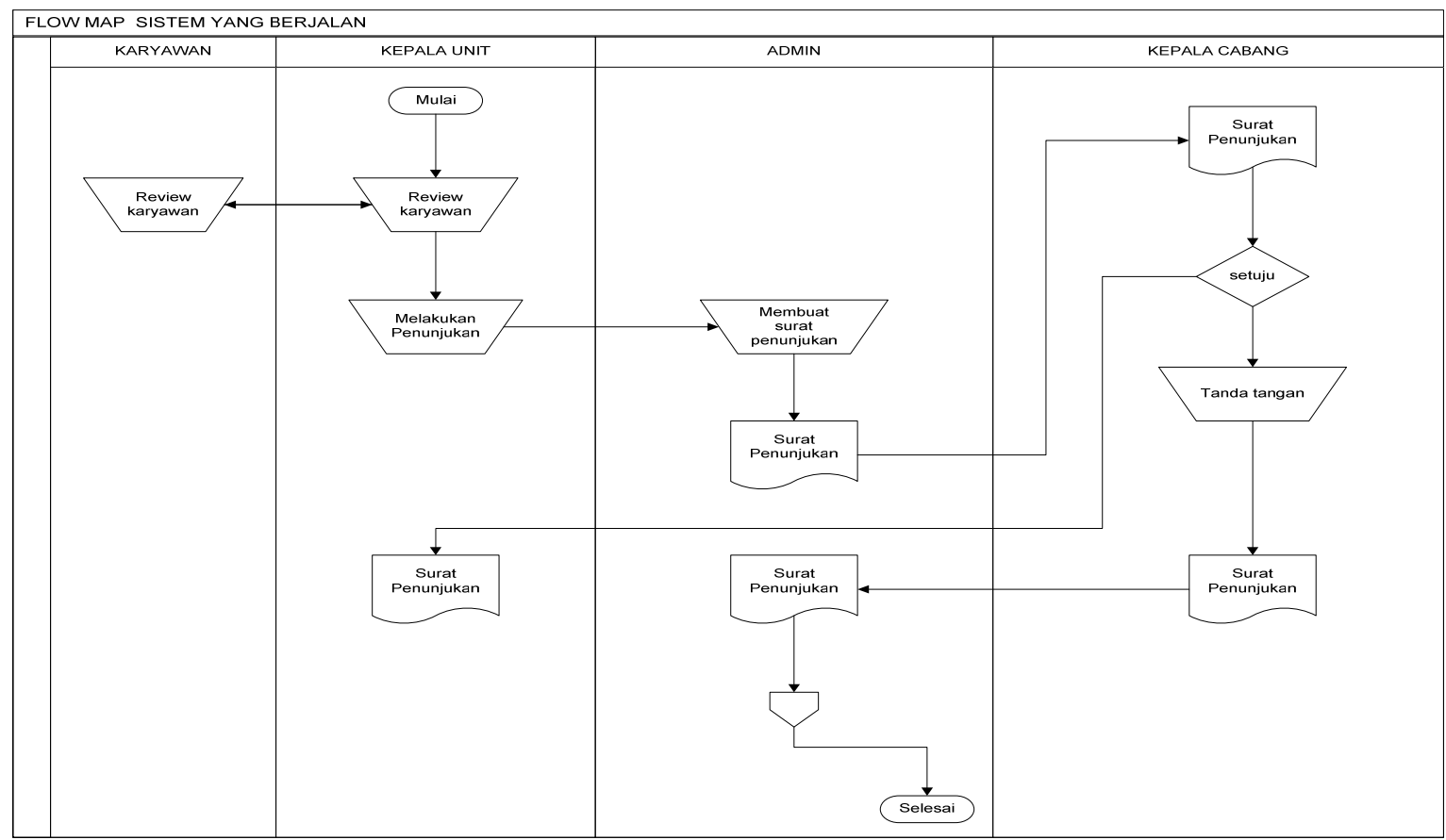

Gambar 1. Flowmap sistem yang sedang berjalan 
Prosedur sistem yang berjalan dimulai dari :

a. Kepala unit menunjuk karyawan untuk menempati posisi jabatan tertentu.

b. Kepala unit menginstruksikan kebagian admin untuk membuatkan surat penunjukan.

c. Bagian admin menyerahkan surat penunjukan keKepala Cabang.

d. Kepala cabang memberikan persetujuan terhadap surat penunjukan, jika setuju surat akan ditandatangani dan selanjutnya diberikan kembali kebagian Admin. Jika Kepala Cabang tidak setuju surat akan diberikan kekepala unit.

\subsection{Analisa Masalah}

Berdasarkan data dan fakta yang telah dikemukakan, masalah yang timbul dari sistem yang berjalan selama ini adalah;
a.
Kepala Cabang kesulitan melakukan pengambilan keputusan yang objectif terkait dengan persetujuan penetapan jabatan yang diajukan oleh Kepala Unit.

b. Dalam melakukan penunjukan jabatan, Kepala Unit belum mempunyai parameter yang objectif. Maka dari itu dibuatkan system penilaian dengan parameter achievement, ability dan process.

c. Pembuatan laporan yang valid dan dapat menampilkan tingkat prestasi karyawan. Pada proses penunjukan karyawan belum terdapat parameter sebagai landasandalam proses penunjukan karyawan.

d. Pengarsipan data karyawan belum bisa diakomodir dengan baik

\subsection{Entity Relationship Diagram}

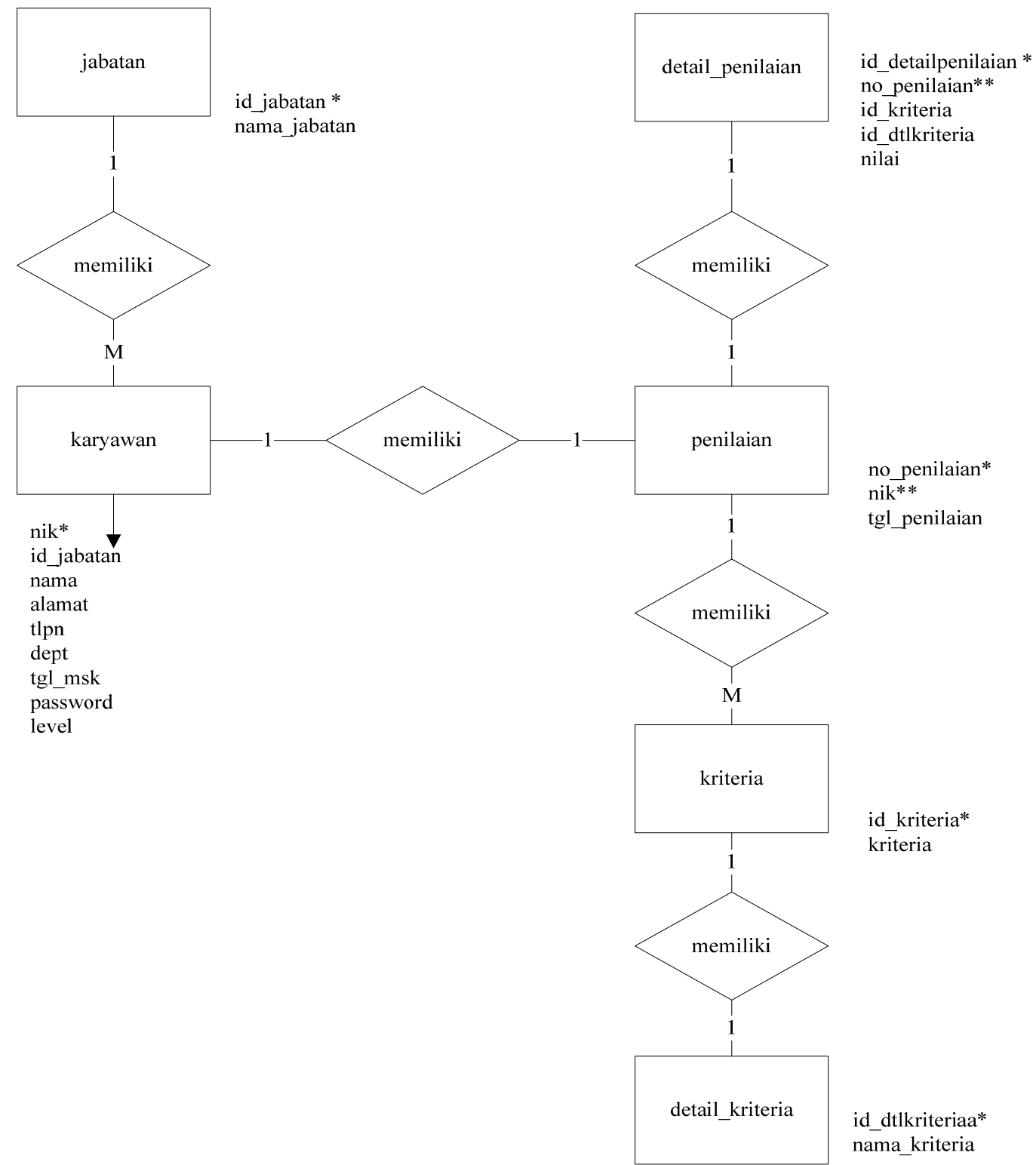

Gambar 2 ERD 


\subsection{Flowmap sistem yang diusulkan}

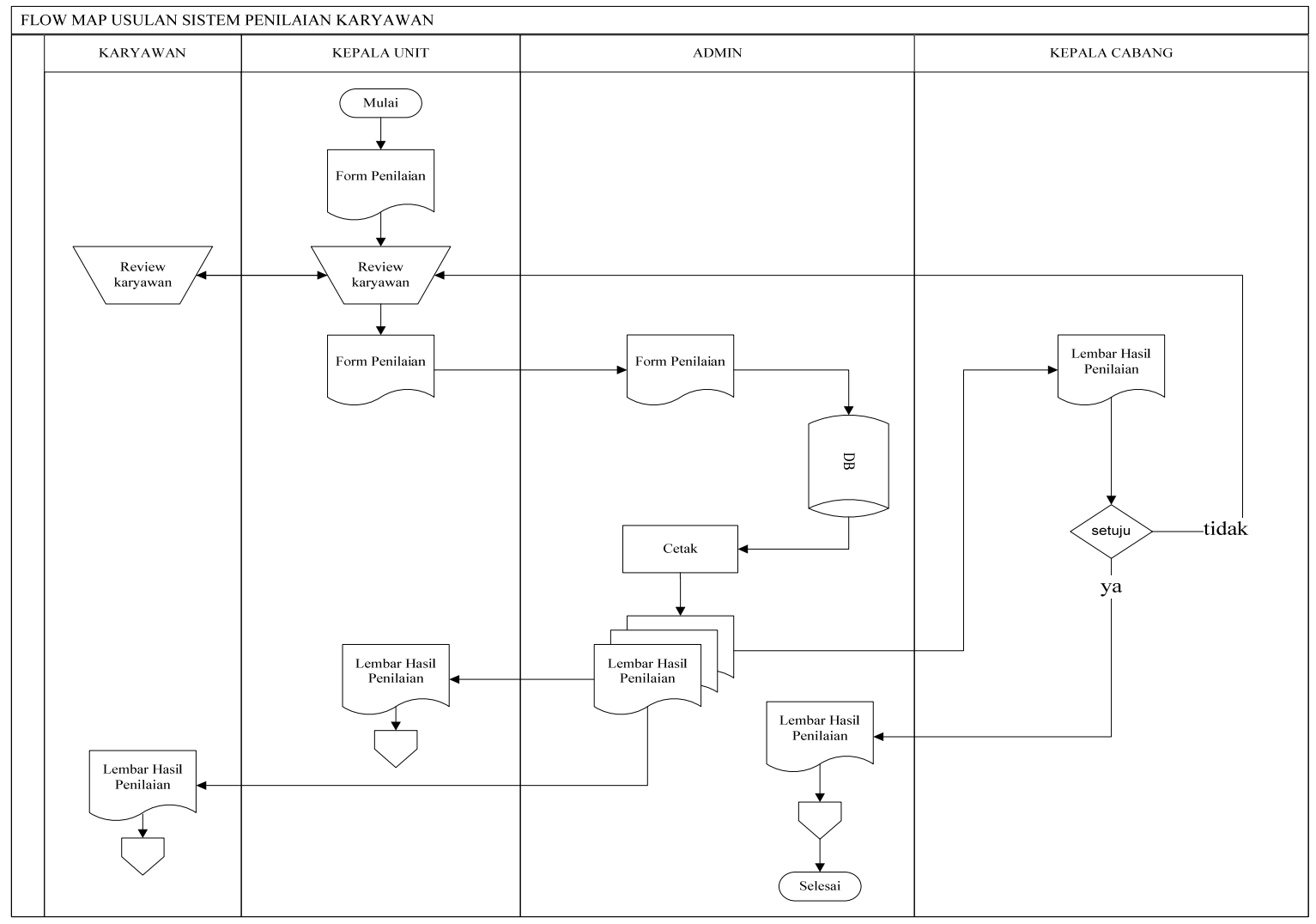

Gambar 3. Flowmap sistem yang diusulkan

Prosedur yang diusulkan dalam pembuatan sistem tersebut adalah:

a. Admin memasukkan criteria penilaian kedalam program.

b. Kepala Unit melakukan penilaian terhadap karyawan melalui kriteria yang sudah ditentukan. c. Hasil penilaian Kepala Unit akan diprosesoleh admin melalui sebuah program, yang selajutnya dapat memunculkan laporan hasil penilaian.

d. Laporan hasil penilaian, oleh bagian Admin diserahkan keKepala Cabang untuk dilakukan persetujuan

\subsection{Diagram Konteks}

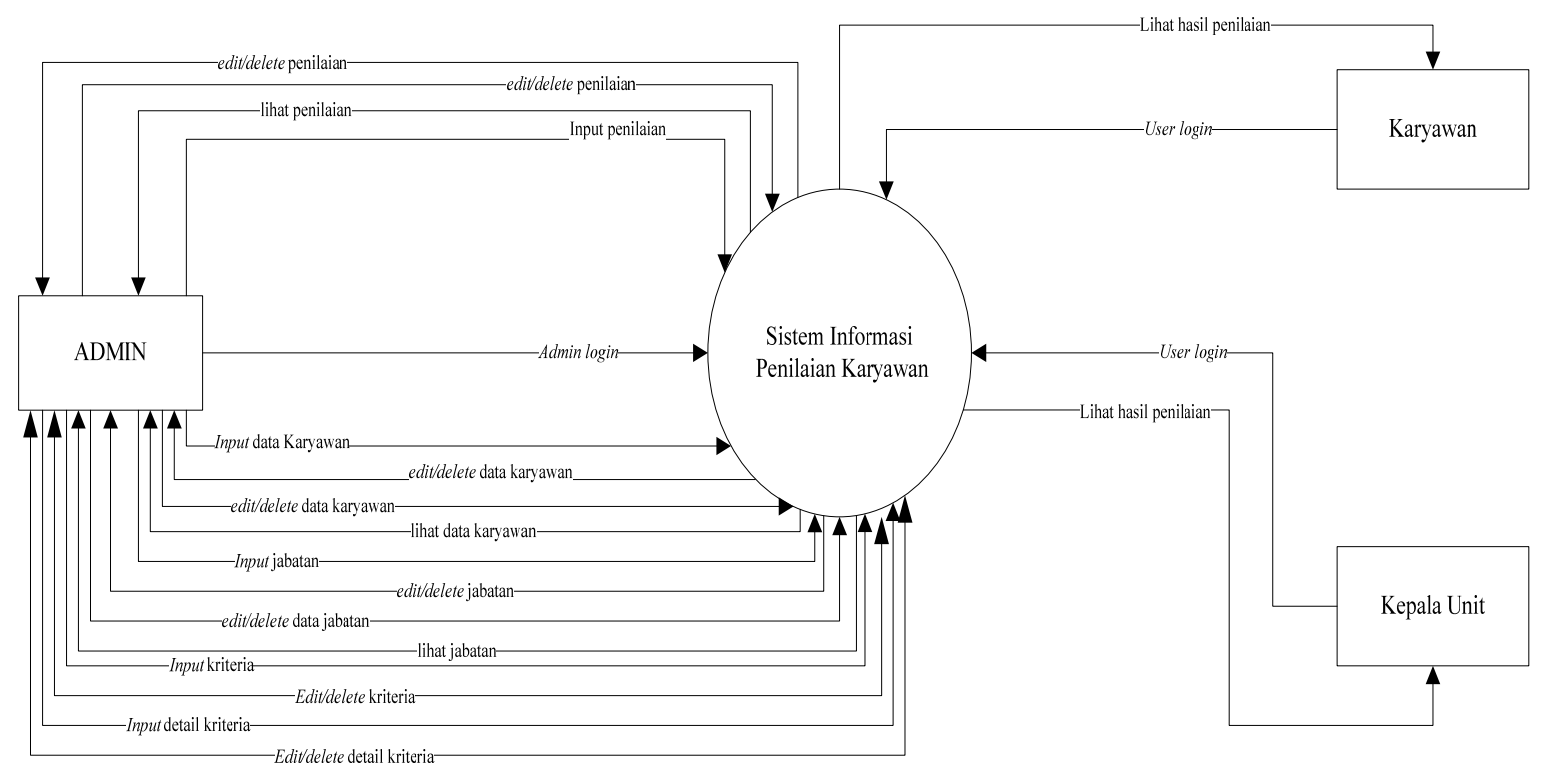

Gambar 4 Diagram Konteks 


\section{Proses Login Administrator}

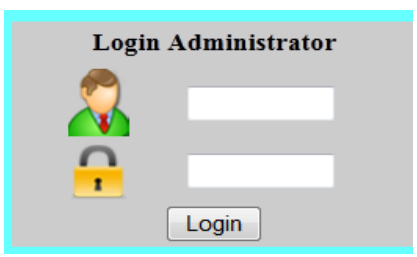

Gambar 5 Form Login

\section{Proses input Nilai karyawan}

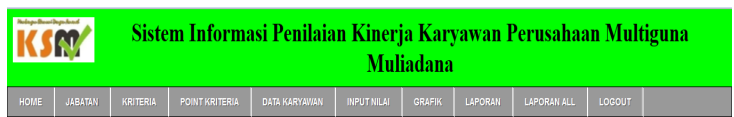

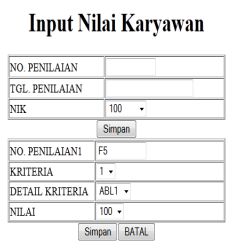

Gambar 6 Form input nilai karyawan

3. Hasil sistem penilaian kinerja karyawan

Hasil dari preview dari Data Penilaian Karyawan, dari form terdapat periode yang menentukan kapan data awal yang dibutuhkan dan berdasarkan NIK.

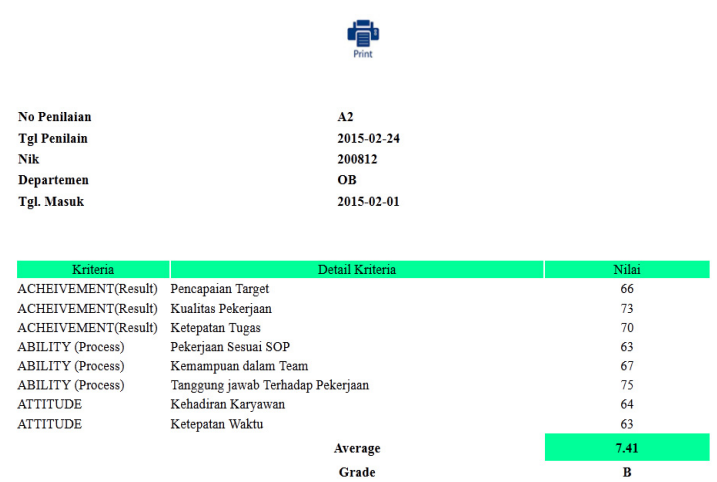

Gambar 7 Hasil Penilaian Kinerja karyawan

4. Hasil Nilai Prestasi karyawan
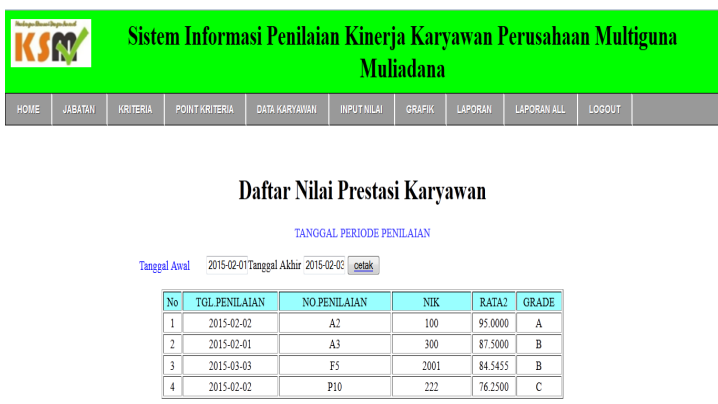

Gambar 8 Hasil Penilaian Seluruh Karyawan
4. KESIMPULAN DAN SARAN

4.1 Kesimpulan

a. Proses penilaian kinerja karyawan yang biasanya dilakukan secara tradisional dilakukan dengan komputer, sehingga penilaian lebih objektif.

b. Aplikasi sistem informasi penilaian karyawan menghasilkan nilai kinerja dan rekap nilai untuk masing-masing karyawan sebagai ukuran kinerja untuk karyawan tiap periodenya.

\subsection{Saran}

a. Dalam proses penyimpanan dan penghitungan hasil penilaian kinerja karyawan sebaiknya membuat dan menggunakan program aplikasi penilaian kinerja yang cepat, tepat, dan akurat sehingga dapat mempermudah proses pencatatan data nilai penilaian kinerja karyawan.

b. Untuk menghasilkan informasi yang cepat dan akurat dalam pencarian data maupun laporan dari penilaian karyawan, perlu digunakan komputer yg mampu menampung atau menyimpan data penilaian kinerja karyawan dalam jumlah besar.

\section{DAFTAR PUSTAKA}

\section{Jurnal}

Harni Mukti Wahyuning. 2015. Sistem Pendukung Keputusan Mutasi Anggota Kepolisian Polresta Palembang Dengan Menggunakan Metode Graphic Rating Scal. Jurnal Sistem Informasi : 1-11

Buku

Bangun, Wilson.(2012).Manajemen Sumber Daya Manusia. Yogyakarta:Erlangga.

Hartono, Jogiyanto. (2008). Pengenalan Komputer: Dasar IImu Komputer, Pemrograman, Sistem Informasi dan Inteligensi Buatan Edisi Lima. Yogyakarta: Andi.

Tata, Sutabri. (2004). Pemrograman Tersetruktur. Yogyakarta: Andi.

\section{Skripsi}

Utomo, Heri Setyo, 2008. Sistem Pendukung Keputusan Penilaian Kinerja Karyawan (Studi Kasus di PT. EterindoNusa Graha Gresik), Tugas Akhir, STIKOM Surabaya. 


\title{
PEMBENTUKAN MODEL KLASIFIKASI DATA LAMA STUDI MAHASISWA STMIK INDONESIA MENGGUNAKAN DECISION TREE DENGAN ALGORITMA NBTREE
}

\author{
Syam Gunawan ${ }^{1}$, Pritasari Palupiningsih ${ }^{2}$ \\ 1,2 Program Studi Sistem Informasi, STMIK Indonesia \\ e-mail: ${ }^{1}$ syam@stmik-indonesia.ac.id, ${ }^{2}$ prita@stmik-indonesia.ac.id
}

\begin{abstract}
ABSTRAK
Salah satu kriteria penilaian pada akreditasi program studi adalah penilaian terhadap lama studi mahasiswa yang lulus tepat waktu. tidak sedikit mahasiwa yang menempuh masa studi melebihi standar kelulusan yang telah ditetapkan. Sehingga penting bagi program studi untuk mengetahui mahasiswa mana saja yang memiliki kemungkinan lulus tidak tepat waktu. Untuk itu diperlukan adanya prediksi lama studi mahasiswa. Salah satu cara untuk dapat memprediksi lama studi mahasiswa adalah dengan membangun model klasifikasi. Penelitian ini bertujuan untuk membangun model prediksi lama studi mahasiswa menggunakan Decision Tree dengan algoritme NBTree. Data yang digunakan adalah data nilai akademik serta data cuti akademik mahasiswa. Hasil yang diperoleh adalah model klasifikasi berupa Naïve Bayes Decision Tree dengan akurasi $73,45 \%$.
\end{abstract}

Kata Kunci: Lama Studi Mahasiswa, Decision Tree, Algoritma NBTree

\section{ABSTRACT}

One of the assessment criteria for the accreditation of the study program is the assessment of the duration of the study of students who graduated on time. not a few students who pursue the study period exceeds the established standard of graduation. So it is important for the study program to know which students have the possibility of passing is not timely. For that it is necessary to predict the length of student study. One way to predict the length of a student's study is to build a classification model. This study aims to build a long prediction model of student study using Decision Tree with NBTree algorithm. The data used are academic value data and student academic leave data. The result obtained is a classification model of Naïve Bayes Decision Tree with $73.45 \%$ accuracy.

Keywords: Duration of Student Studies, Decision Tree, NBTree Algorithm

\section{PENDAHULUAN}

Program Studi merupakan garda terdepan dalam penyelenggaraan pendidikan dari sebuah Perguruan Tinggi, sehingga program studi senantiasa melakukan evaluasi guna meningkatkan mutu dan efisiensi perguruan tinggi termasuk peningkatan kualitas lulusan. Selain itu, salah satu kriteria penilaian pada akreditasi program studi adalah penilaian terhadap lama studi mahasiswa yang lulus tepat waktu. Masa studi mahasiswa telah diatur dalam ketetapan Kementerian Pendidikan dan Kebudayaan Direktorat Jenderal Pendidikan Tinggi tentang Sistem Pendidikan Tinggi yang menyebutkan bahwa untuk memenuhi standar kompetensi lulusan bagi mahasiswa program sarjana (S1) beban wajib yang harus ditempuh adalah paling sedikit 144 - 160 satuan kredit semester ( sks ) dengan masa studi selama 8 - 10 semester atau $4-5$ tahun.

Pada institusi pendidikan perguruan tinggi, data mahasiswa dan data jumlah kelulusan mahasiswa dapat menghasilkan informasi yang berlimpah berupa jumlah kelulusan setiap tahunnya, profil, dan hasil akademik mahasiswa selama menempuh proses kegiatan belajar mengajar di perguruan tinggi. Adanya informasi mengenai lama studi mahasiswa tentu akan menjadi pendukung suatu pengambilan keputusan yang tepat bagi manajemen Perguruan Tinggi dalam mengambil langkah berikutnya.

Permasalahan yang sering terjadi adalah masih banyaknya jumlah mahasiswa yang lulus dengan masa studi melampaui waktu yang telah ditetapkan atau tidak tepat waktu. Hal ini dapat mempengaruhi mutu lulusan Perguruan Tinggi. Sehingga penting bagi program studi untuk mengetahui mahasiswa mana saja yang memiliki kemungkinan lulus tidak tepat waktu. Untuk itu diperlukan adanya prediksi lama studi mahasiswa. Salah satu cara untuk dapat memprediksi lama studi mahasiswa adalah dengan membangun model klasifikasi. Selama ini STMIK Indonesia belum memiliki model klasifikasi lama studi mahasiswa yang dapat digunakan sebagai prediksi jumlah lulus tepat waktu. Padahal data mahasiswa sangat berlimpah, hanya saja data-data tersebut belum dimanfaatkan untuk dianalisis lebih jauh.

Data lama studi mahasiswa berukuran besar dapat dianalisis menggunakan teknik klasifikasi. Salah satu metode dalam klasifikasi adalah decision tree yang akan menghasilkan model klasifikasi. Salah satu algoritma yang dapat diterapkan dalam metode decision tree adalah NBTree. Model klasifikasi yang terbentuk akan dapat digunakan dalam prediksi. Penelitian ini 
bertujuan untuk menerapkan metode decision tree dengan algoritma NBTree untuk membentuk model klasifikasi. Hasil dari penelitian ini adalah terbentuknya model klasifikasi data lama studi mahasiswa STMIK Indonesia yang nantinya dapat digunakan untuk prediksi jumlah mahasiswa lulus tepat waktu.

\section{METODOLOGI PENELITIAN}

Data yang digunakan dalam penelitian ini merupakan data mahasiswa 2013-2015 di STMIK Indonesia. Penelitian ini dilakukan secara bertahap sesuai tahapan yang telah disusun pada Gambar 2. Nilai threshold yang digunakan pada penelitian ini adalah $70 \%$.

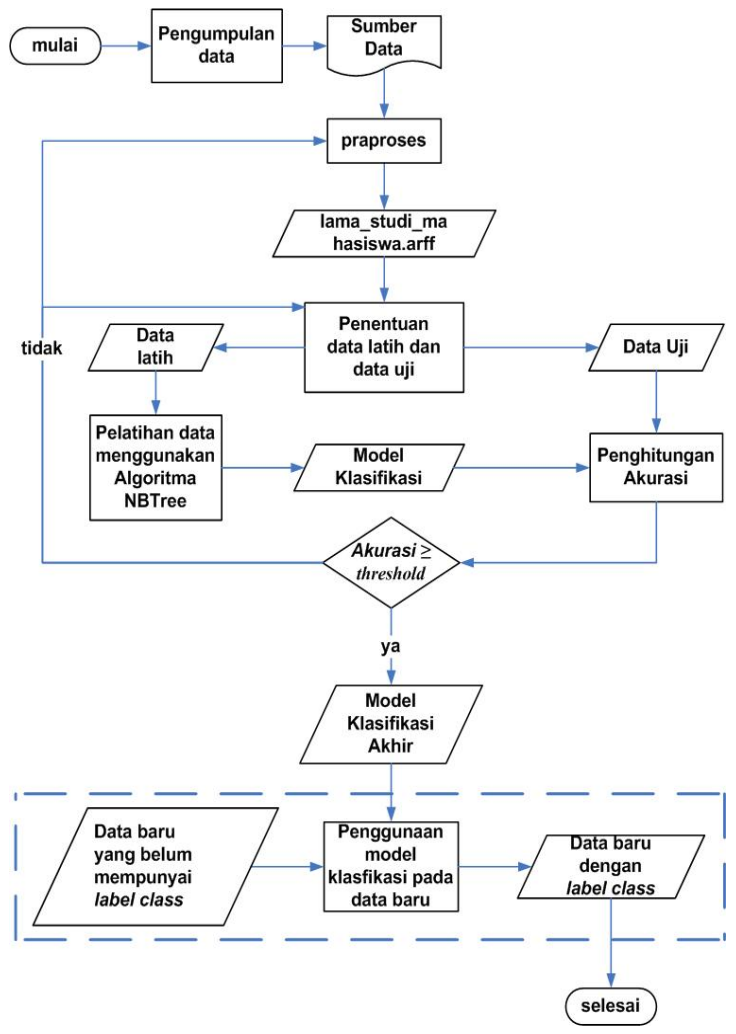

Gambar 2. Metode Penelitian

\subsection{Praproses Data}

Data dari sumber dikumpulkan dan dilakukan tahapan praproses data sebagai berikut :

1. Seleksi data

Pada tahap ini, dilakukan pengelompokkan mahasiswa berdasarkan lama studinya dan memilih atribut-atribut yang sesuai dengan kategori permasalahan.

2. Pembersihan data

Pada data dilakukan pembersihan data untuk memperbaiki data yang hilang atau kosong, data yang mengandung noise, dan data yang tidak konsisten.

3. Integrasi data

Pada tahap ini dilakukan penggabungan data dari berbagai sumber ke suatu basis data. Kemudian dilakukan proses reduksi data, dimana data yang tidak relevan dan data yang redudansi dibuang.

4. Transformasi data

Proses perubahan bentuk ke dalam bentuk data yang tepat agar dapat digunakan untuk proses selanjutnya. Proses ini meliputi penyeragaman nama atribut.

\subsection{Pembagian Data Latih dan Data Uji}

Proses pembagian data menjadi data latih dan data uji dilakukan dengan menggunakan 10 fold cross validation. Data latih akan digunakan untuk membentuk model klasifikasi. Sedangkan data uji akan digunakan untuk menghitung akurasi yang diperoleh dari model klasifikasi.

\subsubsection{Klasifikasi}

Pada proses klasifikasi dilakukan pembentukan model klasifikasi menggunakan metode decision tree. Kemudian dilakukan penghitungan akurasi dari model klasifikasi yang terbentuk. Dari proses klasifikasi ini akan diperoleh model klasifikasi yang dapat digunakan untuk mengisi label kelas dari data baru yang belum diketahui label kelasnya.

\subsubsection{Model Klasifikasi}

Proses pembentukan model klasifikasi dari data mahasiswa menggunakan data tabel gabungan dan kelas targetnya. Pembentukan model klasifikasi ini menggunakan salah satu algoritme pembentukan decision tree yaitu algoritme NBTree.

\subsubsection{Penghitungan Akurasi}

Tahap ini adalah tahap untuk menghitung akurasi dari model klasifikasi yang diperoleh dari proses klasifikasi. Metode yang digunakan dalam proses penghitungan akurasi ini adalah dengan menggunakan confussion matrix.

Jika hasil akurasi yang diperoleh sudah memenuhi nilai threshold, maka model klasifikasi itu akan digunakan untuk menentukan label kelas dari data baru. Akan tetapi jika akurasi yang diperoleh belum memenuhi nilai threshold, maka proses klasifikasi akan diulang dengan menggunakan proporsi data latih dan data uji yang berbeda atau mengulang tahap praproses dengan objek yang berbeda.

\section{HASIL DAN PEMBAHASAN}

\subsection{Praproses Data}

Data yang digunakan pada penelitian ini adalah data nilai akademik mahasiswa, data cuti akademik, dan data ketepatan waktu lulus mahasiswa program studi sistem informasi tahun 2013 - 2015. Tidak semua data yang terdapat pada data nilai akademik mahasiswa digunakan pada penelitian ini. Setelah melalui tahap pemilihan atribut, terdapat 36 atribut yang digunakan pada penelitian ini. Atribut itu terdiri dari 34 mata kuliah semester 1 sampai semester 4, cuti kuliah dan ketepatan lulus studi. Atribut ketepatan lulus studi menjadi kelas dari data yang digunakan pada penelitian ini. 
Proses selanjutnya adalah proses pembersihan data. Salah satu tujuan proses pembersihan data adalah untuk mengganti data yang kosong. Jika terdapat nilai atribut yang kosong untuk suatu record, akan diganti dengan nilai $\mathrm{T}$. Dimana nilai $T$ ini berarti mahasiswa tersebut tidak mengambil mata kuliah tersebut. Hal ini terjadi karena terdapat perbedaan kurikulum antara mahasiswa yang lulus tahun 2013 dengan mahasiswa yang lulus tahun $2014-2015$. Selain itu nilai masing-masing atribut mata kuliah terdiri dari A, B, C, D, dan T. Tidak terdapat nilai E, dikarenakan salah satu persyaratan sidang skripsi adalah tidak terdapat nilai E. Sehingga mahasiswa yang sudah lulus, otomatis tidak memiliki nilai $\mathrm{E}$.
Kemudian masing-masing data tersebut digabungkan menjadi satu.

\subsection{Klasifikasi}

Proses klasifikasi dilakukan dalam dua tahap, yaitu pembentukan model klasifikasi berupa decision tree dan penghitungan akurasi dari decision tree yang terbentuk. Pembentukan decision tree dilakukan dengan menggunakan algoritme NBTree. Proses pembentukannya dilakukan dengan perangkat lunak Weka. Gambar 3 merupakan decision tree yang dibentuk. Pada decision tree yang dihasilkan, diketahui bahwa tidak semua atribut yang digunakan muncul sebagai node pada decision tree.

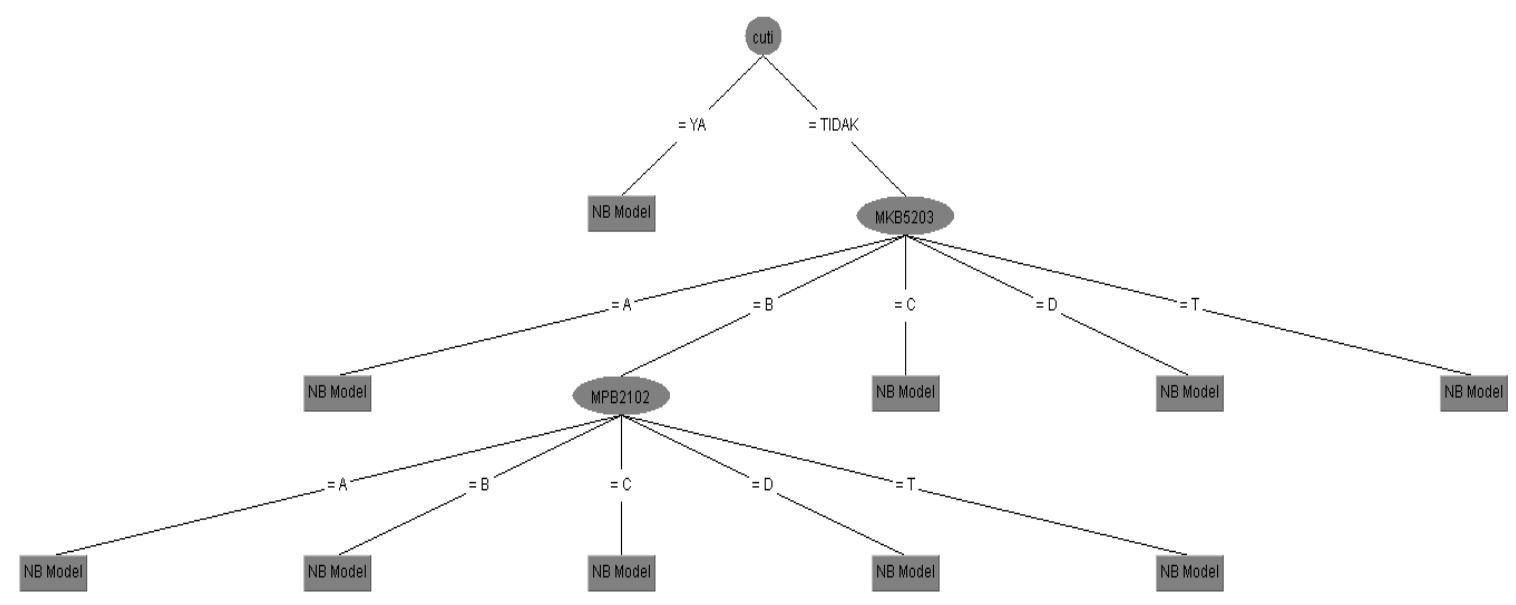

Gambar 3. Model Klasifikasi Data Lama Studi Mahasiswa Program Studi Sistem Informasi STMIK Indonesia

Dari gambar 3 di atas, dapat dilihat bahwa dari 35 atribut yang digunakan, hanya 3 atribut yang muncul pada decision tree tersebut, yaitu cuti kuliah, MKB5203 (Mata kuliah Sistem Operasi) dan MPB2102 (Mata kuliah Komputer dan Masyarakat). Leaf node yang dihasilkan dari decision tree yang dibentuk dari algoritme NBTree merupakan sebuah model naïve bayes, dimana model ini berisi peluang untuk masing-masing kelas, dan peluang setiap atribut terhadap masing-masing kelas.

Berdasarkan decision tree yang terbentuk, dapat dibuat 10 aturan. Sebagai contoh, aturan yang terbentuk dari decision tree pada Gambar 3, adalah sebagai berikut :

- Aturan 1:

Jika nilai atribut cuti adalah YA, maka penentuan kelas dapat dihitung menggunakan model naïve bayes 1 .

- Aturan 6:

Jika nilai atribut cuti adalah TIDAK, niali atribut MKB5203 adalah B, dan nilai atribut MPB2012 adalah A, maka penentuan kelas dapat dihitung menggunakan model naïve bayes 6 .

Nilai yang dihitung dengan menggunakan model naïve bayes adalah conditionally independent antara satu atribut dan atribut lainnya dengan menggunakan persamaan (2). Kemudian dilakukan penghitungan peluang suatu record termasuk ke dalam setiap kelas yang dihitung dengan Persamaan (3). Pengitungan ini dilakukan untuk semua kelas yang ada. Untuk penentuan kelas, diambil berdasarkan nilai peluang suatu record termasuk ke dalam suatu kelas yang paling tinggi.

\subsection{Penghitungan Akurasi}

Untuk menghitung akurasi dari model klasifikasi yang terbentuk digunakan confusion matrix. Confusion matrix yang diperoleh dari model klasifikasi tersebut terdapat pada Tabel 2.

Tabel 2. Confusion matrix dari model klasifikasi

\begin{tabular}{|l|l|l|l|}
\hline \multicolumn{2}{|c|}{} & \multicolumn{2}{|l|}{ Kelas yang diprediksi } \\
\cline { 3 - 4 } \multicolumn{2}{c|}{} & $\begin{array}{l}\text { Kelas }= \\
\text { Tepat }\end{array}$ & $\begin{array}{l}\text { Kelas }= \\
\text { Tidak } \\
\text { Tepat }\end{array}$ \\
\hline \multirow{2}{*}{$\begin{array}{l}\text { Kelas } \\
\text { Aktual }\end{array}$} & Kelas = Tepat & 270 & 35 \\
\cline { 2 - 4 } & $\begin{array}{l}\text { Kelas = Tidak } \\
\text { Tepat }\end{array}$ & 115 & 145 \\
\hline
\end{tabular}

Penghitungan akurasi dengan menggunakan confusion matrix adalah sebagai berikut:

akurasi $=\frac{\text { banyaknya prediksi yang benar }}{\text { total banyaknya prediksi }}$

Dengan menggunakan data pada tabel confusion matrix, dapat dihitung akurasi dari model klasifikasi. 


$$
\begin{array}{r}
\text { akurasi }=\frac{270+145}{565} \\
=\frac{415}{565}=0,7345
\end{array}
$$

Hasil akurasi yang diperoleh adalah $73,45 \%$. Sedangkan nilai threshold yang digunakan adalah $70 \%$. Sehingga nilai akurasi yang diperoleh telah memenuhi threshold yang diberikan.

\section{KESIMPULAN}

\subsection{Kesimpulan}

Berdasarkan penelitian yang dilakukan dalam membentuk model klasifikasi untuk data lama studi mahasiswa, dapat diambil kesimpulan sebagai berikut :

1. Telah terbentuk model klasifikasi untuk yang memiliki 10 aturan klasifikasi dengan akurasi $73,45 \%$.

2. Lama studi mahasiswa dapat dideskripsikan oleh nilai akademik dan data cuti akademik mahasiswa.

\subsection{Saran}

1. Data yang digunakan bisa ditambah lebih dari 3 tahun, agar penelitiannya agar model data klasifikasinya lebih variatif.

2. Gunakan metode penelitian yang lain, agar bisa membandingkan hasil penelitian NBTree

\section{DAFTAR PUSTAKA}

[1] Han J, Kamber M. 2006. Data Mining : Concepts and Techniques. Morgan Kaufman Publisher, San Francisco .

[2] Hastuti K. 2012. Analisis Komparasi Algoritma Klasifikasi Data Mining Untuk Prediksi Mahasiswa Non Aktif. Semarang : Seminar Nasional Teknologi Informasi \& Komunikasi Terapan 2012.

[3] Kohavi R. 1996. Scaling Up the Accuracy of Naïve-Bayes Classifiers : a Decision-Tree Hybrid. AAAI.

[4] Tan P, Michael S, dan Vipin K. 2005. Introduction to Data mining. Pearson Education, Inc, Boston.

[5] Williams N, Zander S, \& Armitage G. 2006. Evaluating Machine Learning Algorithms for Automated Network Application Identification. CAIA. 